\title{
A PRACTICE REVIEW OF 35 CORMACK GRADE 4 DIRECT LARYNGOSCOPIES
}

\author{
J. Adam Law MD, Paul Brousseau BEd, Ian Morris MD, Ronald Cheng MD \\ Department of Anesthesia, Dalhousie University, QEII Health Sciences Centre \\ 1796 Summer Street, Halifax, NS, B3H 3A7
}

\section{INTRODUCTION}

We undertook a retrospective chart and database audit of 24 months' practice at a teaching institution to review incidence and outcomes of Grade 4 laryngoscopies (G4L).

\section{METHODS}

Following ethics board approval, the computerized anesthetic record database was queried for all possible references to 'airway' from Jan 2002 to December 2003. Resultant records were handsearched for any reference to G4L. When identified, the patient's paper chart and electronic anesthetic record were reviewed.

\section{RESULTS}

During the 2-year period, 17800 general anesthetics requiring intubation were performed. 35 G4Ls were recorded, for an incidence of 2/1000. 63\% of the G4Ls were obtained by $11 \%$ of the department membership. Difficult intubation was anticipated in $71 \%$ of cases. Of these anticipated difficult cases, an intermediate-acting non-depolarizing muscle relaxant (NDMR) was used in $64 \%$ of cases and succinylcholine in only 36\%. All except two cases were successfully intubated: one case was awoken and one had surgery proceed with an LMA. In only two cases was difficulty with bag-mask ventilation (BMV) noted (both were rescued with LMA) although specific note of ease of BMV was made in only $43 \%$ of records. Only 2 patients suffered oxygen desaturation to $<90 \%$ (to nadirs of 85 and $88 \%$ ) prior to intubation; no patient required an emergent surgical airway and none had their surgery cancelled. Adjunctive or alternative maneuvers or equipment used in response to the G4L appear in Table 1, with effectiveness.

\begin{tabular}{|c|c|c|c|}
\hline Maneuver used & $\begin{array}{c}\text { \# patients in whom } \\
\text { maneuver or device } \\
\text { tried }\end{array}$ & $\begin{array}{c}\text { If used, successful in \# } \\
(\boldsymbol{\%})\end{array}$ & $\begin{array}{c}\text { If successful, 1st } \\
\text { attempt success rate }\end{array}$ \\
\hline 'BURP' & 6 & $1(17 \%)$ & $\mathrm{n} / \mathrm{a}$ \\
\hline Styletted ETT & 7 & $3(43 \%)$ & $60 \%$ \\
\hline Bougie & 9 & $3(33 \%)$ & $100 \%$ \\
\hline Trachlight TM & 25 & $22(88 \%)$ & $86 \%$ \\
\hline Flexible FOB & 7 & $5(71 \%)$ & $80 \%$ \\
\hline
\end{tabular}

Table 1. Response to G4L. with results

\section{DISCUSSION}

Total incidence of G4L, at $0.02 \%$, was in keeping with previous reports ${ }^{1,2}$. A high percentage of clinicians elected to use a NDMR in the face of anticipated difficult laryngoscopy, possibly representing a shift in practice over the traditional use of succinylcholine. Lightwand use resulted in a high first-attempt success rate. Bougie use was unimpressive. We conclude that encountering a G4L does not necessarily lead to patient morbidity or cancellation of surgery.

\section{REFERENCES}

${ }^{1}$ Can J Anaesth 45: 452-9 $\quad{ }^{2}$ Can J Anaesth 41: 372-83 